DOI: $10.1002 /(($ please add manuscript number $))$

Article type: Full paper

\title{
Designing an Efficient Multi-Mode Environmental Sensor based on Graphene-Silicon Heterojunction
}

Khurram Shehzad ${ }^{1 a}$, Tianjin Shi ${ }^{1,2 a}$, Akeel Qadir ${ }^{1 a}$, Xia Wan ${ }^{1}$, Hongwei Guo ${ }^{1}$, Ayaz Ali ${ }^{1}$,

Weipeng Xuan ${ }^{1}$, Hua Xu ${ }^{3}$, Zhongze $\mathrm{Gu}^{3}$, Xinsheng Peng ${ }^{4}$, Jin Xie ${ }^{5}$, Litao Sun ${ }^{6}$, Qiyuan He ${ }^{7}$, Zhen $X^{8}$, Chao Gao ${ }^{8}$, You-Seung Rim ${ }^{9}$, Yaping Dan ${ }^{10}$, Tawfique Hasan ${ }^{11}$, Pingheng Tan ${ }^{12}$, Erping Li ${ }^{1}$, Wenyan Yin ${ }^{1}$, Zhiyuan Cheng ${ }^{1}$, Bin Yu ${ }^{14}$, Yang Xu ${ }^{1 *}$, Jikui Luo ${ }^{13}$, and Xiangfeng Duan ${ }^{7}$

${ }^{1}$ Key Laboartory of Micro-Nano Electronics and Smart System of Zhejiang Province, College of Information Science and Electronic Engineering and State Key Laboratory of Silicon Materials, Zhejiang University, Hangzhou 310027, China

${ }^{2}$ Hangzhou Hikvision Digital Technology Co., Ltd, Hangzhou 310052, China

${ }^{3}$ State Key Laboratory of Bioelectronics, Southeast University, Nanjing, China

${ }^{4}$ College of Material Science, Zhejiang University, Hangzhou 310027, China

${ }^{5}$ State Key Laboratory of Fluid Power \& Mechatronic systems, Zhejiang University, Hangzhou 310027, China

${ }^{6}$ SEU-FEI Nano-Pico Center, Key Laboratory of MEMS of the Ministry of Education, Southeast University, Nanjing, 210096, China

${ }^{7}$ Department of Chemistry and Biochemistry, University of California, Los Angeles, California 90095, United States

${ }^{8}$ MOE Key Laboratory of Macromolecular Synthesis and Functionalization, Zhejiang University, Hangzhou 310027, China

${ }^{9}$ School of Intelligent Mechatronic Engineering, Sejong University, 209 Neungdong-ro, Gwangjin-gu, Seoul 05006, Republic of Korea

${ }^{10}$ Joint institute of University of Michigan and Shanghai Jiaotong University, Shanghai, China

${ }^{11}$ Cambridge Graphene Centre, University of Cambridge, Cambridge CB3 0FA, UK

${ }^{12}$ State Key Laboratory of Superlattices and Microstructures, Institute of Semiconductors, Chinese Academy of Sciences, Beijing 100083, China 


\title{
WILEY-VCH
}

${ }^{13}$ Inst.itute of Renew.able Energy \& Environment Technologyies, University of Bolton, Bolton BL3 5AB, UK

${ }^{14}$ College of Nanoscale Science and Engineering, State University of New York, New York 12203, U.S.A.

${ }^{a}$ Authors have equal contributions

*Corresponding author email: yangxu-isee@zju.edu.cn, J.Luo@bolton.ac.uk

\begin{abstract}
:
By exploiting the adsorbent gaseous molecules induced changes in intrinsic properties of graphene/silicon (Gr/Si) Schottky junction, we report a sensitive, low-power consuming, multimode environmental sensor. By combining an array of Gr/Si Schottky diodes with a differential amplifier circuit, we are able to not only differentiate the temperature coefficient and humidity sensing, but also monitor the sun-light exposure time. Our device is particularly sensitive towards humidity in both forward and reverse biased, and works in resistive as well as capacitive mode. Sensitivity of our devices reached to $17 \%, 45 \%, 26 \%$, and $32 \%$ per relative humidity $(\% \mathrm{RH})$ for reverse biased, forward biased, resistive, and capacitive modes, respectively. In the reverse mode, the power consumption is as low as $2 \mathrm{nW}$. Moreover, our sensor response is highly selective, with sensitivity lower than $1 \%$ for other gases present in atmosphere including $\mathrm{H}_{2}, \mathrm{O}_{2}, \mathrm{~N}_{2}$, and $\mathrm{CO}_{2}$. High sensitivity, low-power consumption, multiple operation modes, and high selectivity promises application of our sensor for industrial and home safety, environmental monitoring such as indoor \& outdoor air conditions, process monitoring, and others.
\end{abstract}

\section{Introduction}

Sensing of environmental components (gases/vapours, light, temperature, etc.) have been traditionally important in numerous applications including industrial and home safety, environmental surveillance, process monitoring, homeland security, e-agriculture, and others ${ }^{[1-7]}$. Modern technologies such as such as smart grids, smart homes, intelligent transportation and 


\section{WILEY-VCH}

smart cities require new generation of multivariable environmental sensors involving a sensing element with multiresponse mechanism to different elements of environment. ${ }^{[8-11]}$ Capability to develop multivariable sensors and actuators with better sensitivity, wider detection range, faster response, shorter recovery time, low power, and low cost will enable their use industrial internet, which is appealing for new era of smart living. To meet the future demands of environmental monitoring applications, emergence of two-dimensional (2D) nanomaterials may prove a key towards the development of next-generation multivariable sensors. ${ }^{[12-16]}$

The concept of Schottky diodes, developed initially for the contact between a bulk metal and semiconductor, has been extended in recent years to graphene (2D material), as graphenesemiconductor is one of the simplest conceivable devices in a hybrid $2 \mathrm{D} / 3 \mathrm{D}$ semiconductor technology. Indeed, graphene-semiconductor Schottky junction is being studied for applications in photo detection ${ }^{[17-19]}$, fiber communications ${ }^{[20]}$, solar cells ${ }^{[21]}$, barristers ${ }^{[22]}$. Schottky barrier height (SBH) of the graphene-semiconductor junction can be modulated by molecules absorbed on the outer surface of graphene, offering the prospect of using graphene based Schottky diode as a sensing platform for wide range of molecules ${ }^{[23-25]}$. Though Schottky junctions offer sensing capabilities in both forward and reverse biased modes, however, their mechanisms are different. While current in forward bias is mainly determined by the series resistance of the junction, the reverse biased current is due to the junction barrier height, as well as the carrier injection ratio and coupling energy of graphene-semiconductor contact. More importantly, reverse bias operation requires lower power consumption than forward bias operation. Reason being that in forward bias the current is few orders of magnitude higher than the reverse bias, and power consumption $(\mathrm{P})$ is directly related with the current according to the formula $\mathrm{P}=\mathrm{VI}$, where $\mathrm{V}$ is voltage and I is the current. 


\section{WILEY-VCH}

In the present work, with an aim of designing an efficient multi-mode environmental sensor, we fabricate a novel graphene based metal-semiconductor field-effect transistor (MESFET), which is composed of graphene as the channel in the horizontal direction and the graphene contact with silicon in the vertical direction to form a graphene/silicon $(\mathrm{Gr} / \mathrm{Si}) \mathrm{Schottky} \mathrm{junction}$. With this novel 2D MESFET device, we show a multimode sensor that works in forward or reverse biased Schottky junction,, and in resistive as well as capacitive mode, making it a promising candidate for $2 \mathrm{D}$ materials based sensors. Our sensor is also sensitive to temperature and light, enabling us to design an environmental monitoring platform by combining an array of $\mathrm{Gr} / \mathrm{Si}$ Schottky diodes with a differential amplifier circuit.

\section{Results and Discussion}

Figure 1a and $1 \mathrm{~b}$ show the schematic and scanning electron microscope (SEM) image of the graphene based MESFET device ${ }^{[26]}$ ( our CVD grown graphene had mobility of $1815 \mathrm{~cm}^{2} / \mathrm{Vs}$ and Dirac point at $26 \mathrm{~V}$ ). With graphene as the channel, connecting the source and drain electrodes, the device can be tested in the horizontal and vertical working modes. The SEM image confirms that graphene has a good physical contact with both the gold electrode and the bottom silicon window, a pre-requisite for an efficient Schottky junction. Figure 1c shows the $2 \times 2$ array device which can be used for multi-environment monitoring and environmental parameters extraction. With a proper circuit, we can not only get the humidity information, but also that of light and temperature. Figure 1d is the microscope image of one graphene-silicon Schottky contact window. For humidity testing, we need a simulated condition as that of the ambient environment. We designed a test setup (Fig. 1e) for controlled humidity and gases (e.g. $\mathrm{O}_{2}, \mathrm{CO}_{2}$, and $\mathrm{N}_{2}$ ). With dry gases mixed with wet water molecules, different switches, and mass flow controllers (MFCs), we have tested the response of our devices to $\mathrm{N}_{2}$, humidity, $\mathrm{CO}_{2}$, and $\mathrm{O}_{2}$. The home-made testing 


\section{WILEY-VCH}

chamber is shown in Fig. 1f. The top side cover was designed to perform the measurements under the dark as well as the light conditions. The cover for dark condition testing, marked as D in Fig.1f, was a simple metal cover. While, the cover for light testing, marked as L in Fig.1f, had a transparent glass window to allow illumination of the device for photocurrent and in-situ Raman measurement. The test chamber had two pneumatic quick connectors for gas flow in and out, and three SubMiniature version A (SMA) terminals connected to the testing electric equipment.

Figure 2a shows the optical image of graphene covered $\mathrm{Si} / \mathrm{SiO}_{2}$ interface area of Schottky device. Presence of graphene on the $\mathrm{Si}$ and $\mathrm{SiO}_{2}$ step (300nm) was confirmed by Raman mapping on the fabricated devices, which produced a typical Raman spectrum of graphene with characteristics peaks, as shown in Fig. 2b. Two main peaks at $\sim 1589 \mathrm{~cm}^{-1}$ (G peak), and $\sim 2700$ $\mathrm{cm}^{-1}$ (2D peak) were observed from the pristine graphene. They correspond to $\mathrm{E}_{2 \mathrm{~g}}$ phonon at the Brillouin-zone and the overtone of the defect-activated D peak, respectively. ${ }^{[27]}$ The D peak is due to the breathing modes of six-atom rings and requires a defect for its activation. It comes from TO phonons around the $\mathrm{K}$ point, and is active by intervalley double resonance ${ }^{[28]}$ Absence of defect-related D peak ( around $1320 \mathrm{~cm}^{-1}$ ) indicates the high crystalline quality of graphene. $\mathrm{I}(\mathrm{D}) / \mathrm{I}(\mathrm{G})$ peak ratio of less than 1 indicates the high quality of continuous graphene grown by CVD method. ${ }^{[29]} \mathrm{I}(2 \mathrm{D}) / \mathrm{I}(\mathrm{G})$ peak ratio of 4.2, and 2D peak full width at half maximum value of 27.5 indicate that graphene is monolayer. $\mathrm{I}(2 \mathrm{D}) / \mathrm{I}(\mathrm{G})$ is a good indicator of number of graphene layers, and Previous studies ${ }^{[29,30]}$ of CVD-grown graphene have taken a $\mathrm{I}(2 \mathrm{D}) / \mathrm{I}(\mathrm{G}) \geq 2$ to indicate monolayer graphene, $2>\mathrm{I}(2 \mathrm{D}) / \mathrm{I}(\mathrm{G})>1$ for bilayer and $\mathrm{I}(2 \mathrm{D}) / \mathrm{I}(\mathrm{G})<1$ for multilayers. To further characterize the humidity effect on graphene by Raman spectroscopy, we used controlled humidity environment in the test chamber with a glass window to perform in-situ Raman 


\section{WILEY-VCH}

mapping measurements under low, moderate, and high humidity conditions of $25 \%, 50 \%$, and $90 \% \mathrm{RH}$, respectively. There were significant humidity-dependent changes in the Raman spectrum of graphene, i.e. changes in peak positions of the $G$ and 2D modes and $I(2 D) / I(G)$ peak intensity ratio, as indicated in the left panel of Fig. 2c. The average Raman peak parameters extracted from Raman map of $10 \mu \mathrm{m}$ x $10 \mu \mathrm{m}$ graphene area under different humidity conditions are shown in the right panel of Fig. 2c. When graphene/Si device is exposed to humidity, upshift in both $G$ and $2 \mathrm{D}$ bands was observed along with decrease in the $\mathrm{I}(2 \mathrm{D}) / \mathrm{I}(\mathrm{G})$ ratio, which indicates $p$-type doping characteristics due to the water molecules adsorbed on graphene/ $\mathrm{SiO}_{2}$ and graphene/Si interfaces ${ }^{[31,32]}$. Raman $\mathrm{G}$ band, which is associated with Fermi energy of the graphene, stiffened with the increase in the humidity as its value shifted from $1583 \mathrm{~cm}^{-1}$ to 1587 $\mathrm{cm}^{-1}$. Such shift determines that in this case water molecules $p$-doped the graphene by acting as an electron-withdrawing molecule. It is in accordance with previous reports which mention that molecules (including gases and water vapors) with electron-withdrawing or electron-donating capacity can p- or n-dope the sensing layer (graphene, $\mathrm{MoS}_{2}, \mathrm{MoO}_{3}$, etc. $)^{[33-35]}$, respectively. This upshift in the Raman peaks is almost completely reversible after purging the chamber with $\mathrm{N}_{2}$ gas. This indicates that the water molecules experience adsorption/desorption processes during the humidity changes to the Schottky device. Changes in the Fermi energy (indicated by upshift in Raman $G$ band) with the water molecules provides the basics of humidity sensing. Interaction of water molecules with graphene is still a topic of debate. It is believed that due to hydrophobic nature of graphene, at low concentrations, water molecules have their dipole moments in opposite directions, so that they cancel on average. Hence, charge transfers between a graphene sheet and water molecules, which could influence the density of the charge carriers and, consequently, the resistance in graphene, are very small. ${ }^{[36]}$ However, electronic properties 


\section{WILEY-VCH}

of graphene on a substrate can change substantially even with low concentrations of water molecules as they can shift the substrate's impurity bands and change their hybridization with the graphene bands. Hence, water can lead to doping of graphene for much lower adsorbate concentrations than for suspended graphene. ${ }^{[37]}$. At large concentrations of molecules, the dipole moments of the different molecules add up instead of averaging out, leading to a significant total dipole moment that will affect the electronic properties of graphene ${ }^{[36]}$. Since, in our case graphene was supported on $\mathrm{Si}$ substrate, so, we observed change in graphene electronic properties both at low and high humidity.

Since the work function of graphene and $n$-type silicon in our devices is $4.9 \mathrm{eV}$, and $4.05 \mathrm{eV}$ at room temperature, respectively, they are expected to form a Schottky junction ${ }^{[38-40]}$. I-V curves of our devices (Fig. 3a) are indeed characteristic of a Schottky ${ }^{[41]}$. We derived the following J-V characteristic of a Schottky diode using Landauer transport formalism with Crowell-Sze approach for thermionic emission and diffusion of carriers over a barrier

$$
J=\left[\frac{e D_{0}}{\tau_{i}}\left(k_{B} T\right)^{2}\left(\frac{\phi_{b}}{k_{B} T}+1\right)\right] \exp \left(-\sqrt{\chi \delta}-\frac{e \phi_{b}}{k_{B} T}\right)\left[\exp \left(\frac{e(V-I R)}{\eta k_{B} T}\right)-1\right]
$$

where $\phi_{b}$ is the Schottky barrier height, $k_{B}$ the Boltzmann constant, $T$ the absolute temperature, $\eta$ the ideality factor, $e$ the elementary charge, $D_{0}=2 /\left[\pi\left(\hbar v_{F}\right)^{2}\right]$ the density of states of graphene, $\chi$ the average barrier height, $\delta$ the oxide thickness, $v_{F}$ the Fermi velocity in graphene, $\hbar$ the reduced Planck's constant, $V$ the voltage applied across the diode, and $R$ the series resistance. $\tau_{i}^{-1}$ represents the injection rate of carriers from silicon to graphene and is related to the silicongraphene and metal-graphene coupling energy. We did not use the effective traditional Richardson constant $\left(\mathrm{A}^{*}\right)$ to describe the $\mathrm{Gr} / \mathrm{Si}$ Schottky junction, because $\mathrm{A}^{*}$ overestimates the 


\section{WILEY-VCH}

thermionic dark current of graphene/silicon Schottky junction without considering finite density of states of graphene, which is better accounted by the Landauer formula. Equation (1) would be linear for $V_{D} \gg \eta k_{B} T$ until much higher bias voltage $(\sim 1 \mathrm{~V})$ where series resistance starts to dominate. From the slope of this linear segment of the $I-V$ plot, one can determine $\eta$, while the intercept on $y$-axis will give the saturation current, from which the $\mathrm{SBH}$ can be determined ${ }^{[42]}$. The inset in Fig. 3a shows the logarithmic I-V plots for graphene Schottky junctions. Using the plots, with the measured area of $25 \times 10^{-4} \mathrm{~cm}^{2}$, we find $\eta=1.2$, and $\phi_{B}=0.84 \mathrm{eV}$ under dark conditions and very low humidity $(\sim 2 \% \mathrm{RH})$. These values are in close agreement with those reported recently ${ }^{29}$ where $\eta>1$ is commonly observed, which has been attributed to barrier height variation with reverse bias arising from bias dependent work function of graphene, image charge induced Schottky barrier lowering and inhomogeneity.

The I-V characteristic of the Schottky devices was also investigated under different humidity conditions, as shown in Fig. 3b. We tested vertical Schottky junction current under different humidity conditions with the bias voltage sweeping from $-1 \mathrm{~V}$ to $1 \mathrm{~V}$. With the increase in humidity, forward current increases while the reverse current decreases. This is understandable considering that in thermionic emission I-V transportation equation (1), reverse current is inversely related to the $\mathrm{SBH}$, while for the forward bias, the junction resistance is decreased due to the adsorption of water molecules and consequent charge transfer process. For forward biased resistance, compared to the saturation part of the rectifying I-V curve in Fig. 3b (which also depicts the resistance), change was more obvious when we set $V_{g s}=10 \mathrm{~V}$ to reverse bias the Schottky junction, as shown in Fig. 3d (inset shows the resistance (R) and conductance (G) of the graphene channel with the RH). 


\section{WILEY-VCH}

For Schottky characteristics under the different humidity, with Eq. (1), using Fermi level change equation and the Langmuir adsorption model at low humidity condition, we can build a relationship between humidity and the current as below:

$$
\begin{aligned}
& \phi_{B}=E_{D}=-\sqrt{\pi} \hbar v_{F} \sqrt{N_{0}+N_{h}} \\
& N_{h}=N_{h}^{s a t}\left(\frac{K \times R H \times e_{w}^{*}}{1+K \times R H \times e_{w}^{*}}\right)
\end{aligned}
$$

where $E_{D}$ is the Fermi level change, $N_{0}$ is the intrinsic carrier density, $N_{h}$ is the hole doping concentration, $N_{h}^{\text {sat }}$ is the saturated doping concentration constant, $\mathrm{K}$ is the equilibrium constant for distribution of water molecules between graphene and the gas phase, and $e_{w}^{*}$ is the equilibrium vapor pressure of water. At room temperature, $e_{w}^{*}=31.27 \mathrm{mBar}$. For our device, $N_{0}=5 \times 10^{12} \mathrm{~cm}^{-2}, N_{h}$ is related to $\mathrm{RH}$, ranging from $3.50 \times 10^{11} \mathrm{~cm}^{-2}$ to $1.15 \times 10^{12} \mathrm{~cm}^{-2}$. Using approximate fitting, we can get $K=0.18$ and $N_{h}^{\text {sat }}=5.46 \times 10^{12} \mathrm{e} / \mathrm{cm}^{-2}$. Thus for lower and moderate humidity conditions, the Langmuir adsorption fits well from 5\% 40\% RH (solid lines Fig. 3c) where SBH increases with humidity, but at the higher humidity conditions it deviates from the standard behavior (dashed lines in Fig. 3c), because the assumption of monolayer coverage only in Langmuir adsorption model is not valid anymore at high humidity conditions.

The above mentioned observations can be explained by considering previous reports ${ }^{[25,43]}$, which mention that charge transfer between adsorbed molecules and graphene decreases as the graphene Fermi level moves closer to the defect level introduced by the adsorbed molecules. We suggest that water molecules absorbed on the surface of graphene induces $p$-type doping, as evidenced by the upward shift of Raman G peak with increasing humidity. This behavior is expected, since $\mathrm{H}_{2} \mathrm{O}$ being an electron acceptor would increase the density of holes in graphene 


\section{WILEY-VCH}

following adsorption and increase its conductivity. ${ }^{[43]}$ This decreases the channel resistance, consistent with the forward biasing condition of the junction. On the other hand, for vertical Schottky junction, this increases the SBH. Figure 4a schematically shows the band structure of $\mathrm{Gr} / \mathrm{Si}$ under low and high humidity conditions.

In contrast to the I-V curves of Schottky junctions which are dominated by the local leakage current, the capacitance is an average collective response of charge effects on the Schottky barrier and the dielectric interface. Thus, monitoring the capacitance changes of the device is also useful for estimating the overall relative humidity environments. Capacitance-voltage (C-V) measurement under different humidity conditions (Fig. 3e) demonstrates that the capacitance of our device increases with humidity, consistent with the observation in $\operatorname{Re}^{[44]}$. From low to high humidity ( $10 \%$ to $90 \% \mathrm{RH})$ a $\sim 27 \%$ increase in the capacitance is observed at $1 \mathrm{kHz}$, proving that our devices are also suitable for capacitance based humidity sensors. In frequency-dependent capacitance measurement, electrons usually have much higher mobility than that of holes and protons. Thus for higher frequency, the capacitance seems smaller due to the "heavier" carriers which cannot catch up with the frequencies. While for higher humidity, more carriers from protons and electrons are brought to the charging and discharge process, thus larger capacitance is observed.

By setting the current at $5 \% \mathrm{RH}$ low humidity $\left(I_{5}\right)$ as a reference, we defined the sensitivity of the vertical part of Schottky junction at relative humidity condition $X$ as:

$$
\text { Schottky }_{S}=\frac{I_{X}-I_{5}}{I_{5} \times\left(R H_{X}-R H_{5}\right)} \times 100 \%
$$

Similarly, the sensitivity for resistance and capacitance is defined, respectively, as: 


\section{WILEY-VCH}

$$
\begin{gathered}
\text { Resistance }_{S}=\frac{R_{X}-R_{5}}{R_{5} \times\left(R H_{X}-R H_{5}\right)} \times 100 \% \\
\text { Capacitance }_{S}=\frac{C_{X}-C_{5}}{C_{5} \times\left(R H_{X}-R H_{5}\right)} \times 100 \%
\end{gathered}
$$

Sensitivity of our devices reach to $17 \%, 45 \%, 26 \%$, and $32 \%$ per $\% \mathrm{RH}$ for reverse biased, forward biased, resistive, and capacitive modes, respectively, as shown in Fig. 3f.

When exposed to visible light, our humidity sensors in all the humidity conditions (from low $2 \% \mathrm{RH}$ to high $90 \% \mathrm{RH}$ ), exhibited a significant change in the reverse and forward biased current Fig. 4b. This demonstrates its ability to simultaneously detect the visible light (570 nm). Origin of photocurrent in our devices can be attributed to photo-generated carriers in $\mathrm{Si}$, which can be extracted through graphene channel before their recombination. It is important to mention that even for photo-current the Schottky junction plays an important part as depletion region and built-in electric field $\left(E_{\text {built-in }}\right)$ associated with it allow the separation of electron-hole pairs rapidly without diffusing, producing a high photo response.

Combining with a simple time-count circuit, we can calculate the total sunlight exposure time as well as the humidity, which allows us construct an environmental monitoring platform which is critical for vegetables, fruits, and plants grown condition control and monitoring. More interestingly, our Schottky sensors can and work at low-powered mode, which is also important for energy-saving and green environments by alleviating the mandatory needs of electric power cables, considering the outdoor environment monitoring and e-agriculture fields are scattered in the large areas up to thousands of acres.

To study the time response of our multi-functional environmental sensor, we tested the current and capacitance change over time shown; panel of Fig. 4c. The rise (response) and the fall 


\section{WILEY-VCH}

(recovery) times are defined as the time required for the current to increase from $10 \%$ to $90 \%$ and drop from $90 \%$ to $10 \%$, respectively, when the humidity is changed to a certain level. Rise time $\left(t_{r}\right)$, and fall time $\left(t_{f}\right)$ for our device on resistive mode were recorded as $\sim 8 \mathrm{~s}$ and $\sim 19 \mathrm{~s}$ (from high humidity levels $(40 \% \mathrm{RH})$ to the initial value $(\sim 20 \% \mathrm{RH}))$, respectively. Response time of our devices is only moderately fast and is limited by the time for the humidity condition control process to pump/purge time the test chamber. Slow absorption and desorption process of the water molecules also contributes to the slow time response. By using better apparatus with fast control on the humidity conditions may improve the response time. Moreover, heating of the device to facilitate the desorption process of water molecules can also improve the fall time. For the reverse bias mode, $t_{r}$ and $t_{f}$ were $\sim 4 \mathrm{~s}$ and $\sim 10 \mathrm{~s}$ (from $20 \% \mathrm{RH}$ to $40 \% \mathrm{RH}$ ). We note that since our target of humidity monitoring is to be applied for applications such as outdoor environment, e-agriculture, and ambient weather conditions, response time is not the most critical parameter of the sensors. However, we would like to mention that compared to other resistive $^{[34,45-48]}$, capacitive ${ }^{[49,50]}$, transistor ${ }^{[35][51]}$ or impedance ${ }^{[49,52]}$ type devices based on sensing materials such as graphene ${ }^{[14,46,49,53-58]}$, metal oxides ${ }^{[34,47,48,52,59,60]}$, metal sulfides ${ }^{[35,}$ ${ }^{48]}$, carbon nanotubes, and black phosphorous, our devices were still comparatively faster ( comparison is provided in the Table.1). Only few devices based on GO in impedance mode ${ }^{[49]}$, GO in optics mode ${ }^{[57]}$, graphene in resistance mode ${ }^{[46]}$, and $\mathrm{ZnO} / \mathrm{GO}$ based SAW devices ${ }^{[58]}$ showed faster response/recovery times. Compared to previously reported similar devices ${ }^{[14,46,49}$, ${ }^{53-58]}$, our device offer the advantage of multi-mode (capacitive and resistive, forward and reverse bais mode), multi-variable (temperature, humidity, light) sensing. Moreover, our devices in both resistive and capacitive mode, showed excellent reversibility, for $>1000$ cycle of change in humidity, with initial resistance and capacitance recovering to $\sim 100 \%$ after we purged the test 


\section{WILEY-VCH}

chamber with dry nitrogen to bring the high humidity level $(90 \% \mathrm{RH})$ to the initial value $(\sim 2 \%$ $\mathrm{RH})$. It is also important to mention that most of the results from the literature tabulated in the Table 1 are with pristine sensing material. In some cases the sensing layer can be modified with different moieties such as metal nano particles (NP) to obtain enhanced sensing response ${ }^{[61-63]}$. For example, deposition of $\mathrm{Pd} \mathrm{NP}$ on $\mathrm{MoS}_{2}$ has been found to enhance the gas response to $\mathrm{NH}_{3}$ by increasing the overall active sensing surface area and the adsorption sites of gas molecules. ${ }^{[62,}$ 63]

The bottom panel of Fig. 4c shows the time response of our devices under both humidity and sun-light conditions (by AM 1.5 solar simulator). Here, the I, II, III, IV are denoted as four different states of our device, i.e. light only, light \& humidity, humidity only, and no light \& no humidity, which are color-marked as periwinkle, mauve, pink and white, respectively. The multimodes of monitoring sunlight and humidity at the same time might be more appealing for eagriculture and outdoor monitoring application. An array of Schottky sensors with four devices are fabricated to monitor different environmental conditions, namely, sun-light only (Device A), sun-light \& humidity (Device B), humidity only (Device C), no sun-light \& no humidity exposure (Device D), respectively as shown in Fig. 1c of the $2 \times 2$ array device. By using a simple differential amplifier circuit, we not only can monitor the sun-light exposure time under different humidity conditions, but can also differentiate the temperature coefficient with humidity sensing. Figure $4 \mathrm{~d}$ shows the temperature induced changes in the current response under different humidity conditions. Figure $4 d$ also presents the sensitivity of our temperature sensor at ambient humidity conditions. Equation 1 describes the change in the current of a Schottky junction with temperature as both have an inverse relation. Temperature range for the response was measured between 10 to $90^{\circ} \mathrm{C}$. For example, temperature coefficients $(\alpha)$ for 


\section{WILEY-VCH}

reverse and the forward current in the room temperature at $5 \% \mathrm{RH}$ are $0.074 \mathrm{nA} / \mathrm{K}, 0.02551$ $\mu \mathrm{A} / \mathrm{K}$, respectively.

Real atmosphere does not contain only the humidity but is a mix of different gases such as $\mathrm{N}_{2}$ (78.09\%), $\mathrm{O}_{2}(20.95 \%), \operatorname{Ar}(0.93 \%)$, and $\mathrm{CO}_{2}(0.038 \%)^{[10]}$. Presence of these gases interferes with the humidity sensing. In particular, graphene based devices, especially CVD graphene, are extremely sensitive to a wide varieties of adsorbent molecules (gases, biological molecules, etc. ${ }^{[64-67]}$, which if present, can interfere with the humidity measurements. Our humidity sensors were highly selective towards humidity. As can be seen in Fig. 4e, sensitivity of our sensors towards the interfering gases present in the atmosphere was almost zero $(<1 \%)$ (both in capacitive and resistive modes), we suggest that this is to the very low absorption probability of these non-polar molecules at the charged $\mathrm{Gr} / \mathrm{Si}$ surfaces is much less than the polar water molecules. We noticed that the sensitivity towards these gases was measured in their $100 \%$ environment, therefore the measuring conditions had higher gas concentrations than in the real atmosphere.

To demonstrate the practical applications of our devices, we simultaneously measured the $\mathrm{RH}$ and the temperature in controlled (clean room, green house) and un-controlled conditions (outdoor, office). Results are provided in Fig. 5, where outdoor (un-controlled) conditions on a rainy day were perfectly demonstrated by the high humidity recordings on the sensors. Moreover, the wide temperature and humidity fluctuations recorded over the period of 15 hours of a day, including morning, afternoon and evening/night demonstrate the robustness of our sensors. For more stable/controlled conditions of green house, clean room, and the office temperature and $\mathrm{RH}$ recordings remained stable over the period of 15 hours which matched very well with the conditions. 


\section{WILEY-VCH}

\section{Conclusions}

In conclusion, we report a highly sensitive, selective, and multi-mode humidity sensor arrays. Mechanism of such ultra-high sensitive response involves the alteration in SBH of Schottky junction, due to the change in Fermi level of graphene when water molecules adsorb on the surface of $\mathrm{Gr} / \mathrm{Si}$ Schottky junction. Our sensor was non-responsive (sensitivity $<1 \%$ ) towards interfering gases in the environment including $\mathrm{N}_{2}, \mathrm{O}_{2}, \mathrm{Ar}$, and $\mathrm{CO}_{2}$, making our sensor highly selective. Based on the high selectivity, combined with multi-mode function and high sensitivity, we envisage the applications of our sensors in diverse areas including e-agriculture, fisheries \& livestock, storage rooms, cooling chambers, swimming pools, as well as indoor \& outdoor local weather monitoring.

\section{Methods:}

The substrate used was n-type (100) $\mathrm{Si}$ wafer (resistivity of 1-10 $\Omega \mathrm{cm}$ ) with $300 \mathrm{~nm}$ thick $\mathrm{SiO}_{2}$ layer. First, the electrode of $\mathrm{Au} / \mathrm{Cr}(60 / 5 \mathrm{~nm})$ used as source and drain of the MESFET device was fabricated by lithography and e-beam evaporation with lift-off process. After a second lithography process, the sample was put into buffered oxide etchant (BOE) to expose the $\mathrm{Si}$ window of the size $500 \mu \mathrm{m} \times 500 \mu \mathrm{m}$. Subsequently, a monolayer chemical vapor deposition (CVD) graphene as the conducting channel was transferred onto the Si window with a conformal coverage to form the Schottky junction. $\mathrm{O}_{2}$ plasma was used to pattern the graphene. Finally, the eutectic GaIn was painted on the back side of Si substrate forming Ohmic contact, and was used as the back-gate electrode. Raman spectroscopy of graphene on $\mathrm{SiO}_{2}$ was conducted using a RENISHAW RM2000 with $532 \mathrm{~nm}$ laser. The I-V and C-V curves were measured with Agilent Semiconductor Analyzer B1500. The AM1.5 solar simulator was used as the light source made by Beijing NBET Technology Co. 


\section{WILEY-VCH}

\section{Acknowledgments}

This work is supported by NSFC (Grant Nos. 61674127, 61274123, 61474099, 61431014, 51650110494, 21325417, and 51533008, and Key Project No. 61431014), ZJ-NSF (LZ17F040001), China State Key Project (2016YFA0200204), China Postdoctoral Science Foundation （2015M571868） , and micro-/nano-fabrication platform of Zhejiang University, and the Fundamental Research Funds for the Central Universities (2016XZZX001-05), and USA National Science Foundation (DMR1508144). This work is also supported by ZJU Cyber Scholarship and Cyrus Tang Center for Sensor Materials and Applications, the Open Research Fund of State Key Laboratory of Bioelectronics, Southeast University, the Open Research Fund of State Key Laboratory of Nanodevices and Applications at Chinese Academy of Sciences (No.14ZS01), and Fellowship of Churchill College at University of Cambridge.

Received: ((will be filled in by the editorial staff))

Revised: ((will be filled in by the editorial staff)) Published online: ((will be filled in by the editorial staff)) 
(a)

(c)
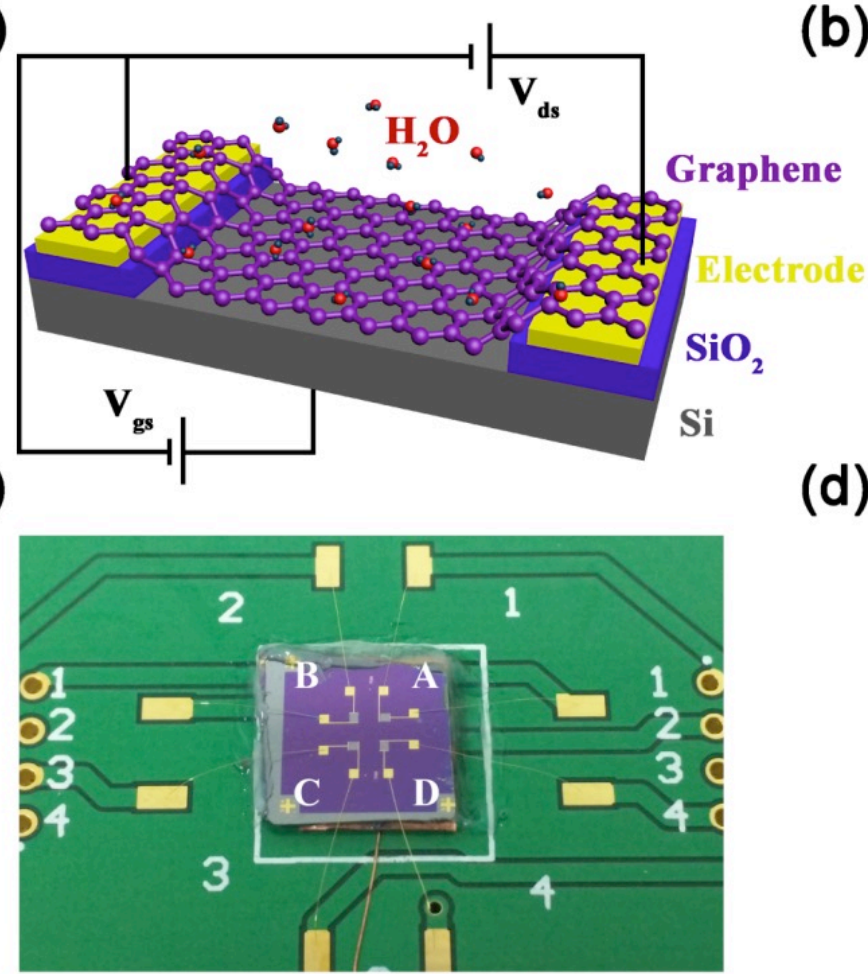

(e)

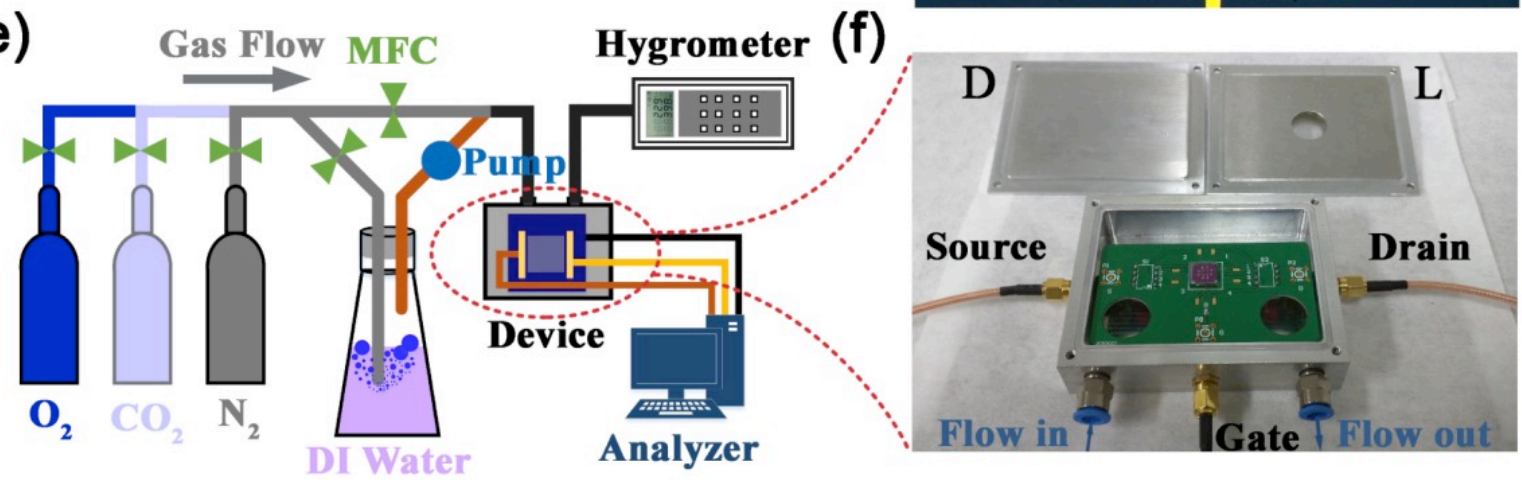

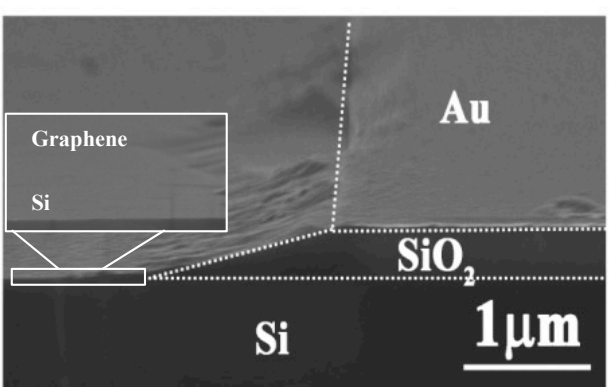

(d)

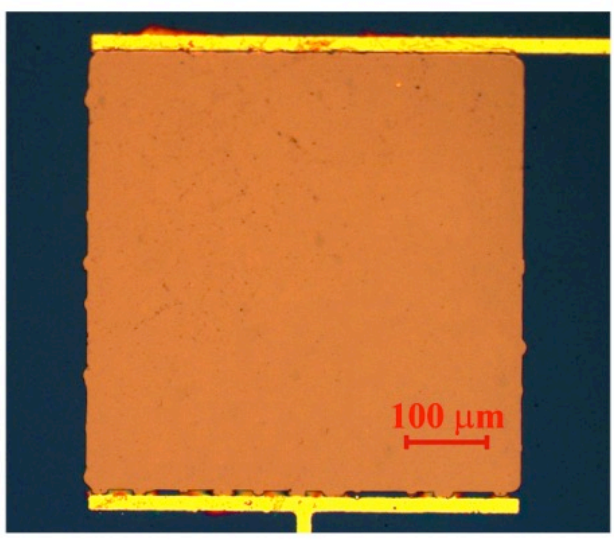

D $L$

Figure 1 (a) Schematic of the multimode humidity sensor with source-drain voltage $V_{\mathrm{ds}}$ and gate voltage $V_{\mathrm{gs}}$ control. (b) SEM of the graphene-silicon interface of a humidity sensor, (c) The $2 \times 2$ array of humidity sensors with four devices, exposing to different conditions, namely, sun-light only (Device A), sun-light and humidity (Device B), humidity Only (Device C), no sun-light and no humidity expose (Device D), respectively. (d) The optical image of a graphene-silicon multimode humidity sensor. Magnified inset image shows higher resolution $\mathrm{Gr} / \mathrm{Si}$ interface. (e) The measurement system setup and (f) the homemade humidity controllable chamber with electric input/outputs. In (f), the left side metal cover with no holes (D) is used under dark conditions, and the right side cover with a transparent glass window (L) is used for sunlight testing as well as Raman characterization. 
(a)

(b)
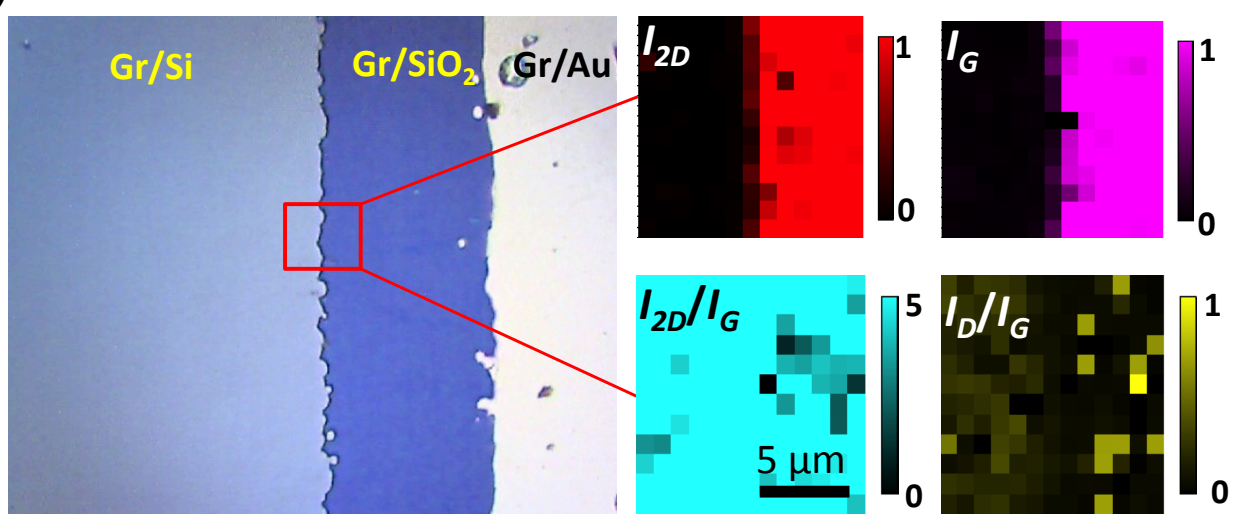

(c)
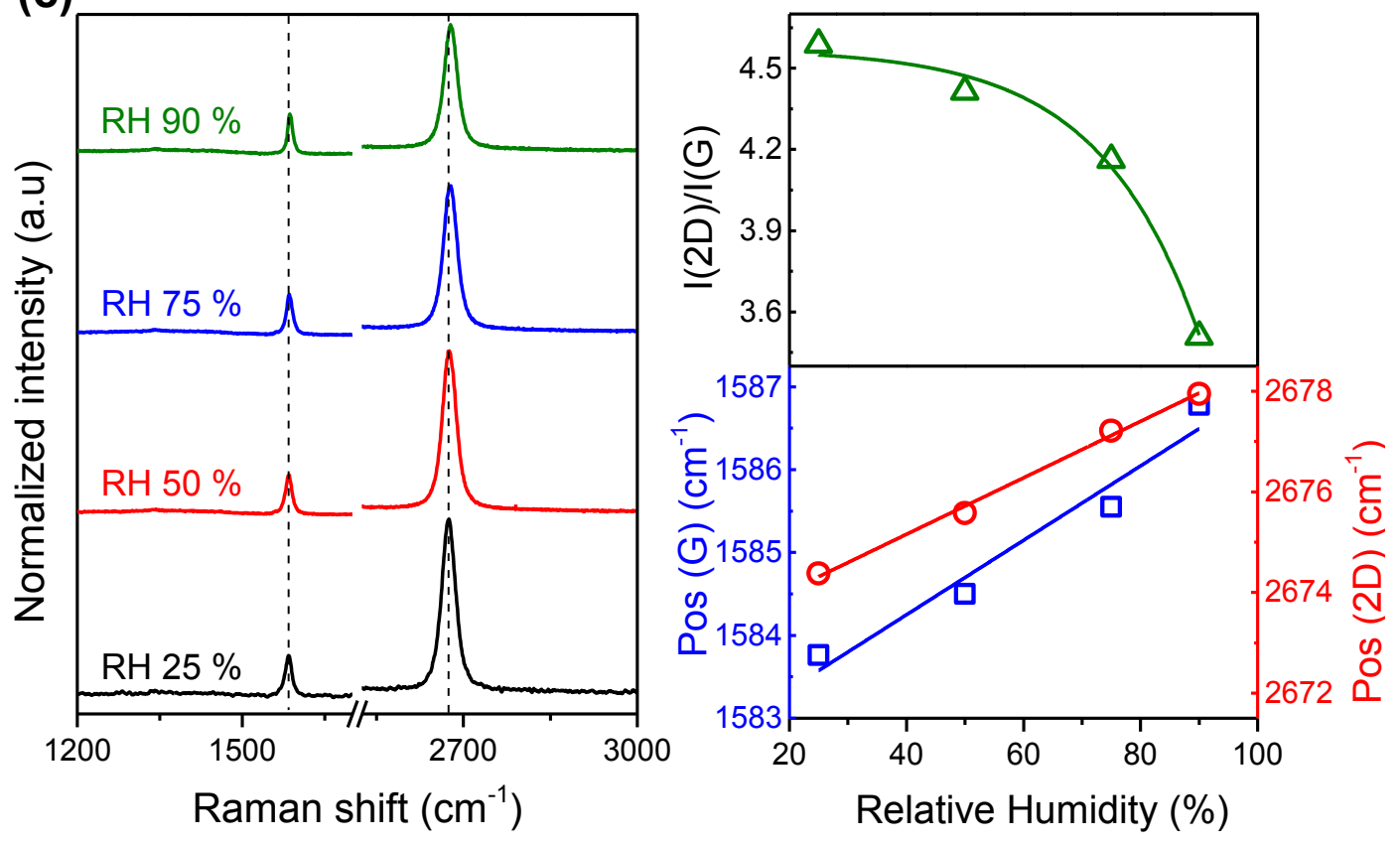

Figure 2 (a) Optical Image of graphene covered $\mathrm{Si} / \mathrm{SiO}_{2}$ interface area of Schottky device. (b) Raman mapping of single layer CVD graphene on to the device area of $(12 \mu \mathrm{m} \times 12 \mu \mathrm{m}) \mathrm{Si} / \mathrm{SiO}_{2}$ interface as highlighted with red rectangle. (c) Raman spectra of graphene on $\mathrm{SiO}_{2}$ area under various humidity conditions (left panel), average peak parameters extracted from Raman mapping of $10 \times 10 \mu \mathrm{m}$ under low, moderate, and high humidity conditions (right panel). 
WILEY-VCH

(a)

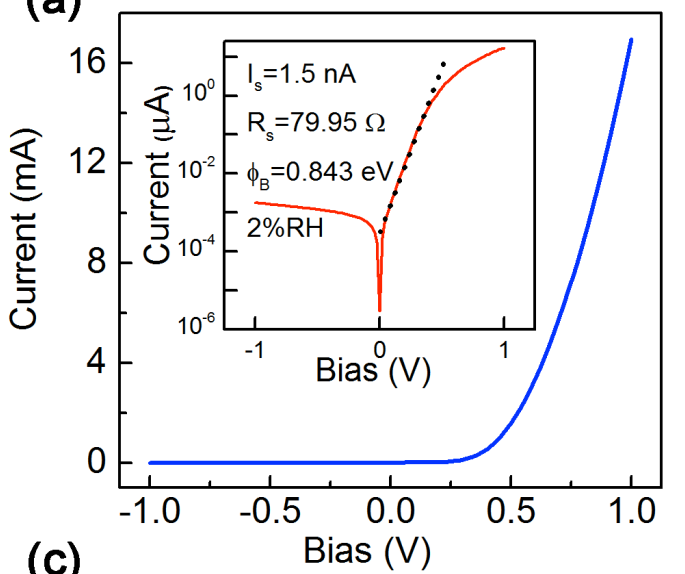

(b)

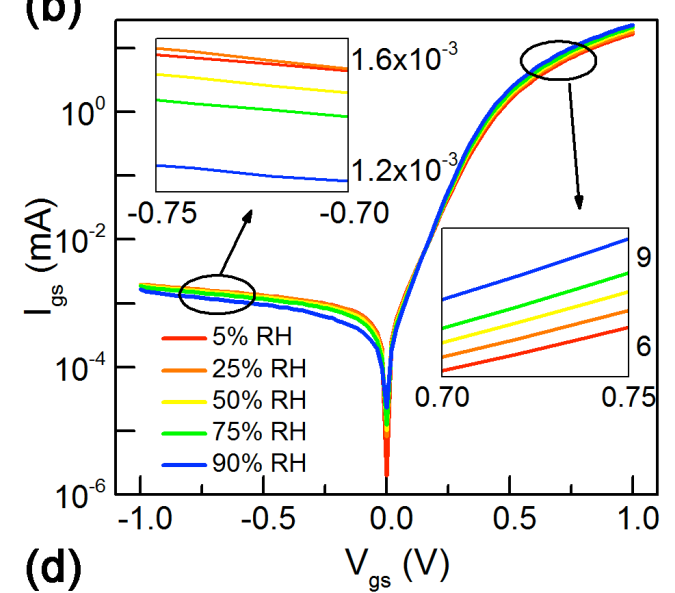

(d)

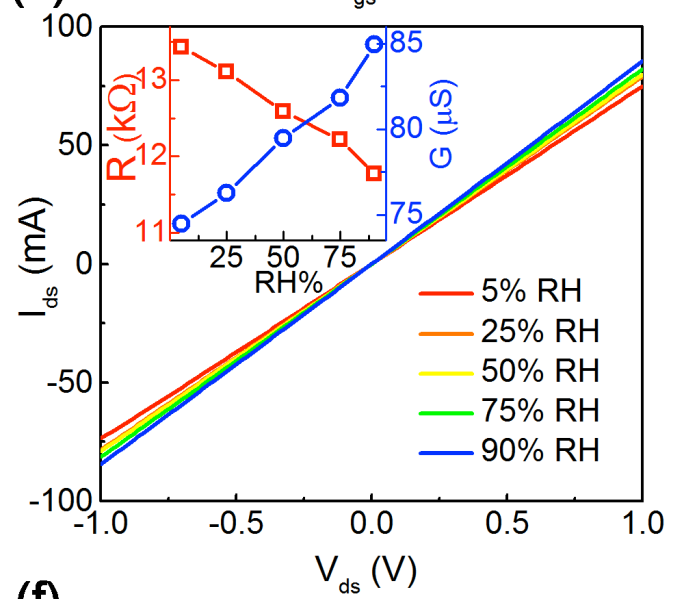

(f)

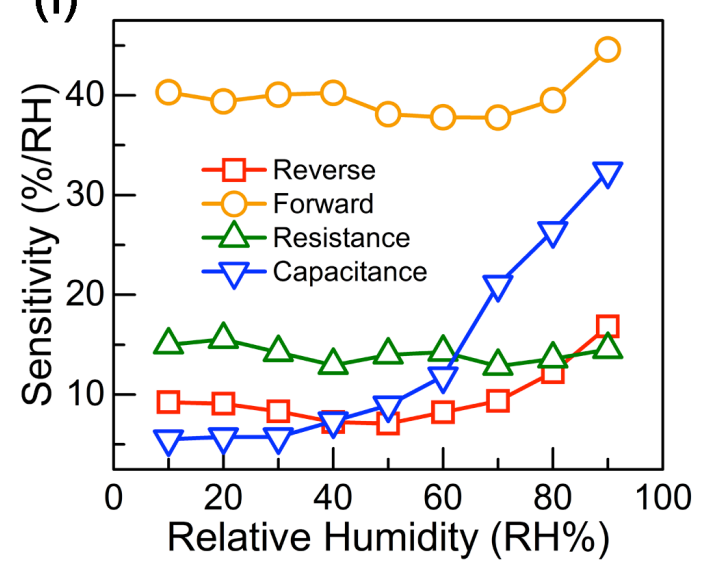

Figure 3 (a) In very low humidity condition $(2 \% \mathrm{RH})$, the I-V characteristic of the vertical Schottky junction of our MESFET device, (b) I-V curves under various humidity conditions, (c) experimental and theoretical (Langmuir adsorption model) Schottky barrier height change with humidity, (d) the horizontal graphene channel current with the sweeping voltage of the source and drain $\left(\mathrm{I}_{\mathrm{ds}}\right)$ with $\mathrm{V}_{\mathrm{gs}}=10 \mathrm{~V}$. Inset of $(\mathrm{d})$ is the resistance and conductance relationship with humidity, (e) capacitance against humidity relation, (f) sensitivity of our humidity sensors under current and capacitance modes. 
(a)

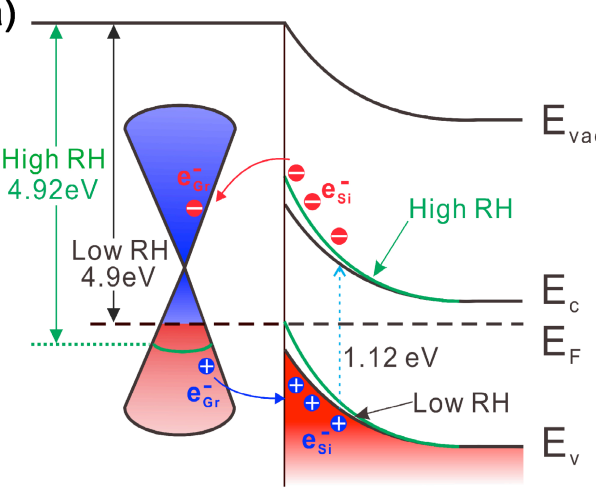

Graphene n-Si

(c)

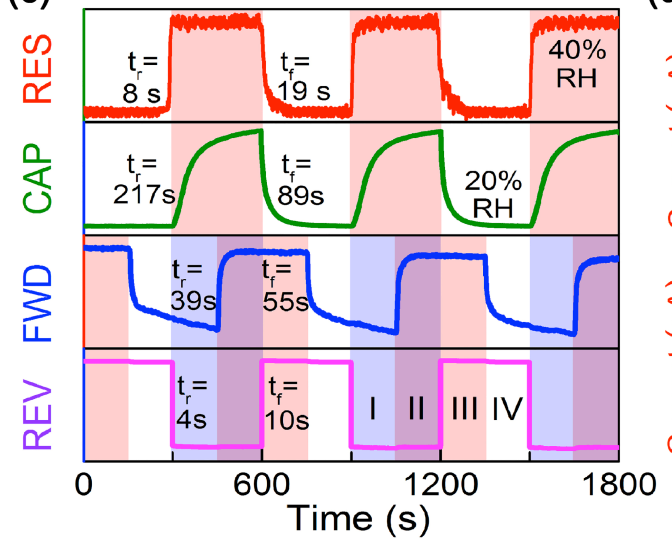

(b)

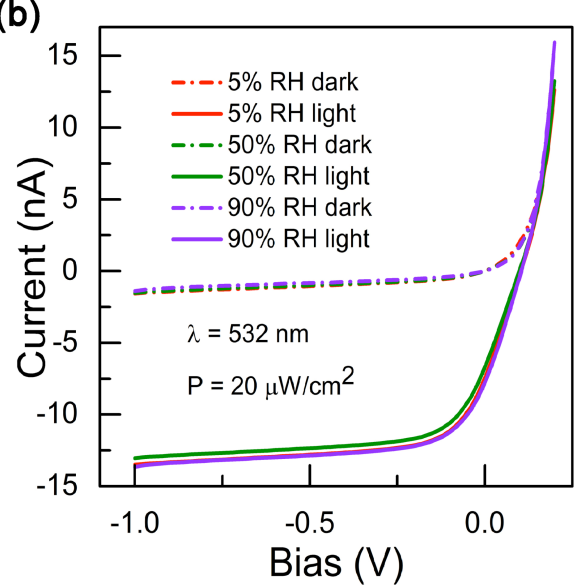

(d)

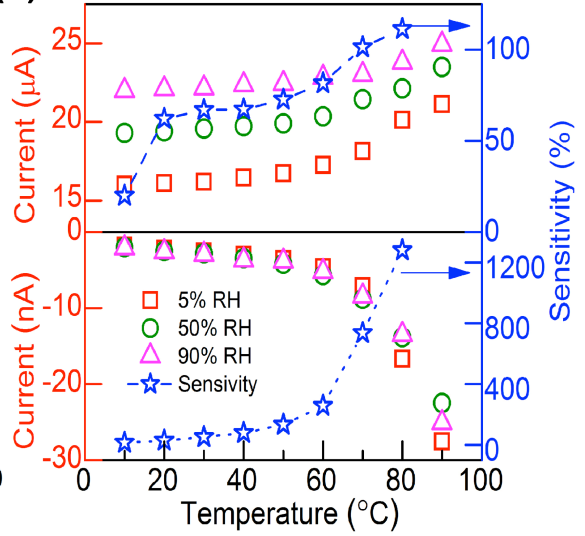

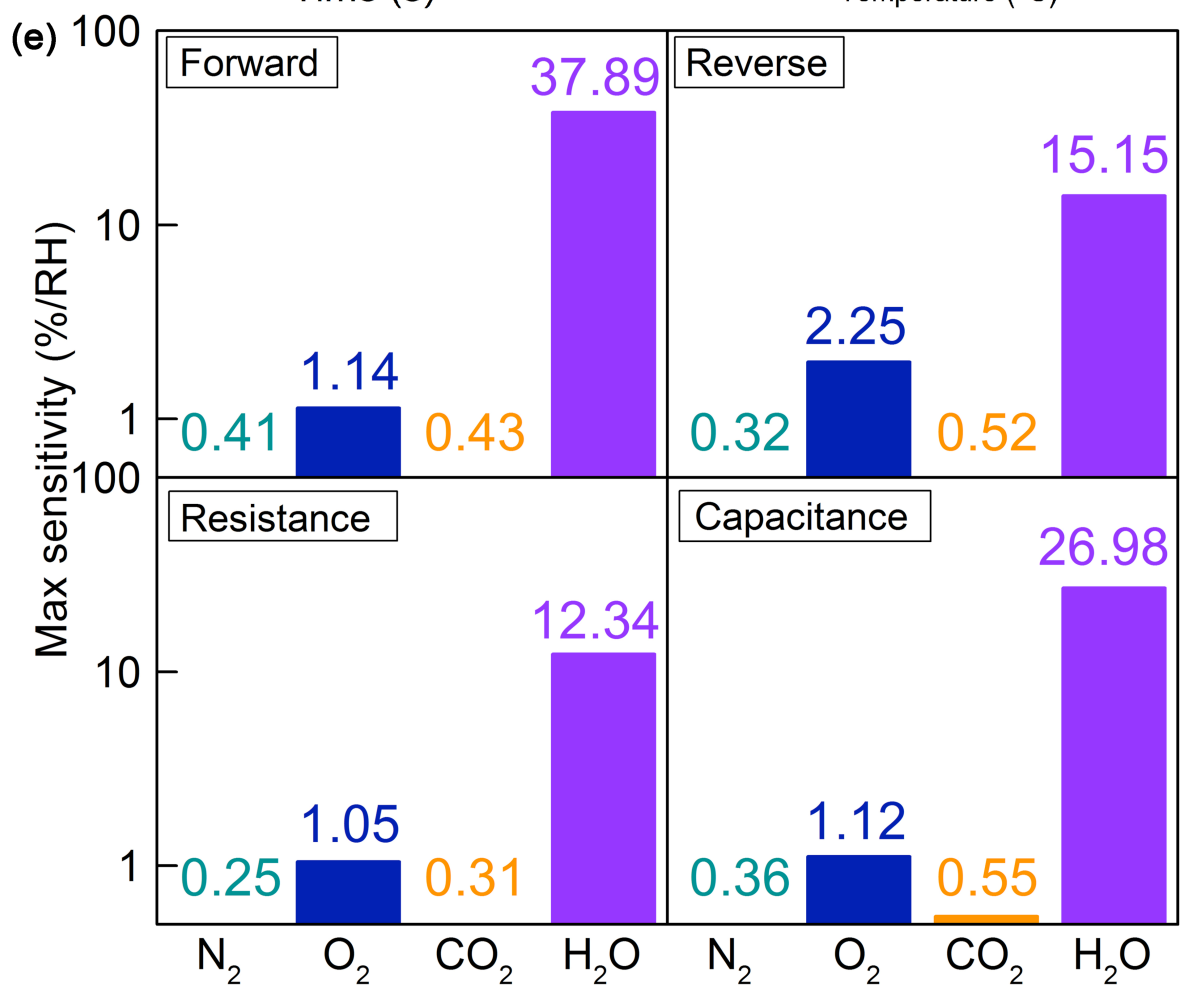




\section{WILEY-VCH}

Figure 4 (a) band structure alignment of graphene-silicon Schottky junction under low $(2 \% \mathrm{RH})$ and high (90\%RH) humidity condition from $\mathrm{C}-\mathrm{V}$ and $\mathrm{I}-\mathrm{V}$ analysis in Fig. 3, the water molecules $p$-dope graphene and increases the Schottky barrier height as well as the conductivity of graphene. (b) The reverse saturation current under low, moderate and high humidity conditions with dark and compact visible laser light $\left(\lambda=532 \mathrm{~nm}, \mathrm{P}=20 \mu \mathrm{W} / \mathrm{cm}^{2}\right)$. (c) The time responses of our sensors at different working modes between low $(20 \% \mathrm{RH})$ and high $(40 \% \mathrm{RH})$ humidity condition, namely, reverse biased (REV), forward biased (FWD), resistive (RES), and capacitive (CAP) modes. By combining with an AM1.5 solar simulator and our humidity controller, the sensor devices work at four different states are also demonstrated, i.e. light with $20 \% \mathrm{RH}$ low humidity (state I), light with $40 \% \mathrm{RH}$ high humidity (state II), no light with $40 \% \mathrm{RH}$ high humidity (state III), no light with $20 \% \mathrm{RH}$ low humidity (state IV), which are marked as periwinkle, mauve, pink and white respectively. (d) The temperature coefficient of our humidity sensor. The temperature coefficients $\alpha=0.074 \mathrm{nA} / \mathrm{K}, 0.02551 \mu \mathrm{A} / \mathrm{K}$ in the room temperature at $5 \%$ RH are obtained at reverse bias and forward bias, respectively. Left axis shows the sensitivity of our

temperature sensors at ambient conditions. (e) Sensitivity/selectivity of our multimode humidity sensor to different environment gases and humidity. 


\section{WILEY-VCH}

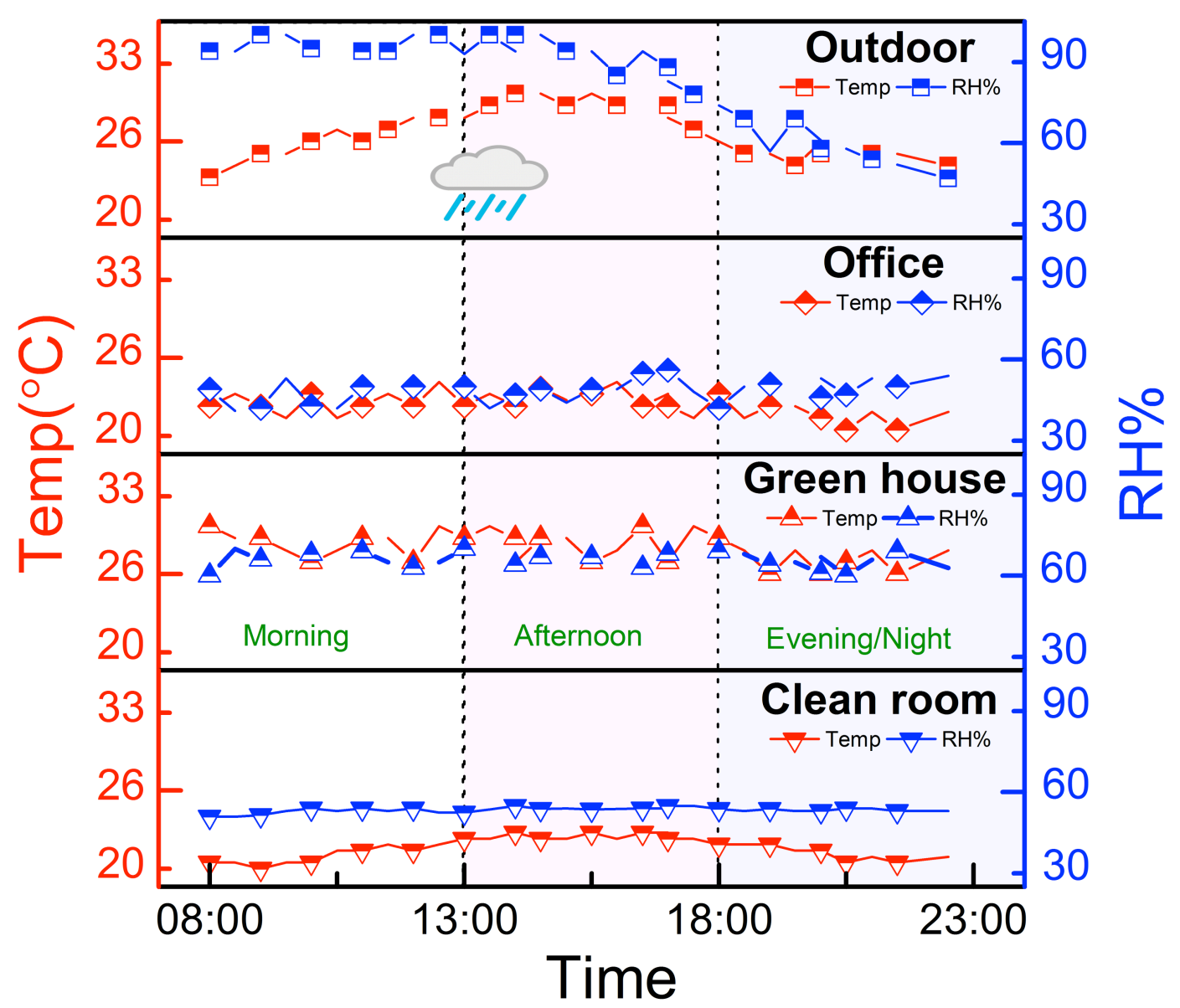

Figure 5. RH and temperature recordings of outdoor, office, green house, and clean room conditions over the 15-hour period of a day including morning, afternoon, and evening/night. 
Table 1 Comparison of state-of-the-art humidity sensors

\begin{tabular}{|c|c|c|c|c|c|}
\hline Sensor type & $\begin{array}{l}\text { Sensing } \\
\text { material }\end{array}$ & Sensitivity (\%) & $\begin{array}{c}\text { Response / } \\
\text { recovery time (s) }\end{array}$ & Power & Ref. \\
\hline $\begin{array}{c}\text { Resistance \& } \\
\text { Reverse Biased }\end{array}$ & $\begin{array}{c}\text { Graphene/Si } \\
\text { Schottky } \\
\text { Junction }\end{array}$ & $\begin{array}{l}45 \% / \mathrm{RH}(\Delta \mathrm{I} / \mathrm{I} \\
\Delta \% \mathrm{RH}) \\
32 \% / \mathrm{RH}(\Delta \mathrm{C} / \mathrm{C} \\
\Delta \% \mathrm{RH})\end{array}$ & $\begin{array}{l}8 / 19 \\
4 / 10\end{array}$ & $\begin{array}{c}2 \mathrm{nW} \\
-\end{array}$ & $\begin{array}{l}\text { This } \\
\text { work }\end{array}$ \\
\hline Impedance & $\mathrm{GO}$ & - & $0.03 / 0.03$ & - & [49] \\
\hline Capacitance & $\mathrm{GO}$ & $37800 \%(\Delta \mathrm{C} / \mathrm{C})$ & $10.5 / 41$ & - & [53] \\
\hline Resistance & Graphene & $\begin{array}{c}31 \%(\Delta \mathrm{R} / \mathrm{R} \Delta \% \mathrm{RH} \\
)\end{array}$ & $0.6 / 0.4$ & $5 \mathrm{~mW}$ & {$[46]$} \\
\hline Resistance & Graphene & $35 \%(\Delta R / R)$ & $108 / 94$ & $8 \mathrm{~mW}$ & {$[54]$} \\
\hline Resistance & Graphene & $80 \%(\Delta \mathrm{R} / \mathrm{R})$ & & & [14] \\
\hline QCM-type & $\mathrm{GO}$ & $22.1 \mathrm{~Hz} / \% \mathrm{RH}$ & $12 / 18$ & - & {$[55]$} \\
\hline Piezoelectricity & $\mathrm{ZnO}$ & $14 \mathrm{kHz} / \% \mathrm{RH}$ & $25 / 25$ & - & {$[56]$} \\
\hline Optics & $\mathrm{GO}$ & $55.3(\mathrm{~dB} / \% \mathrm{RH})$ & $0.67 / 0.67$ & - & [57] \\
\hline SAW & $\mathrm{GO}, \mathrm{ZnO}$ & $53 \mathrm{kHz} / \% \mathrm{RH}$ & $1 / 19$ & - & {$[58]$} \\
\hline $\begin{array}{l}\text { Resistance \& } \\
\text { Capacitance }\end{array}$ & DNA & - & $26 / 78$ & $3 \mathrm{~mW}$ & {$[68]$} \\
\hline Resistive & $\mathrm{GO}$ & $0.14 \mathrm{mV} / \% \mathrm{RH}$ & $189 \pm 49 / 89 \pm 5$ & $2.75 \mathrm{~mW}$ & {$[45]$} \\
\hline Capacitance & $\begin{array}{l}\text { Carbon } \\
\text { Nanotube }\end{array}$ & $\begin{array}{c}35.86 \% / \% \mathrm{RH}(\Delta \\
\mathrm{C} / \Delta \% \mathrm{RH})\end{array}$ & $75 / 140$ & - & {$[50]$} \\
\hline Transistor & $\mathrm{SnO}_{2}$ & $3500 \%\left(\mathrm{I}_{\mathrm{RH}} / \mathrm{I}_{\text {dry }}\right)$ & $120-170 / 20-60$ & $1 \mu \mathrm{W}$ & [59] \\
\hline
\end{tabular}


WILEY-VCH

\begin{tabular}{|c|c|c|c|c|c|}
\hline Capacitance & $\gamma-\mathrm{Al}_{2} \mathrm{O}_{3}$ & $9.378(\mathrm{pF} / \mathrm{RH})$ & $150 / 52$ & - & {$[60]$} \\
\hline Transistor & $\mathrm{MoS}_{2}$ & $800 \%(\Delta \mathrm{R} / \mathrm{R})$ & $\sim 300, \sim 600$ & $2.52 \mathrm{nW}$ & {$[35]$} \\
\hline Transistor & Black & $521 \%(\Delta \mathrm{R} / \mathrm{R})$ & $\sim 101 / \sim 26$ & $70 \mathrm{nW}$ & {$[51]$} \\
\hline Resphorus & Phostance & Black & $97 \%(\Delta \mathrm{R} / \mathrm{R})$ & $360 / 10$ & \\
\hline Resistance & $\mathrm{Phoshorus}_{2} \mathrm{O}_{5}$ & $45.3 \%(\Delta \mathrm{R} / \mathrm{R})$ & $240 / 300$ & \\
\hline Impedance & $\mathrm{Fe}_{2} \mathrm{O}_{3}$ & $99 \%(\Delta \mathrm{Z} / \mathrm{Z})$ & $29 / 630$ & \\
\hline Resistance & $\mathrm{MoO}_{3}$ & $229 \%(\Delta \mathrm{R} / \mathrm{R})$ & $118 / 5$ & \\
\hline Resistance & $\mathrm{SnS}_{2}$ & $11300 \%(\Delta \mathrm{R} / \mathrm{R})$ & $85 / 6$ & \\
\hline
\end{tabular}




\section{WILEY-VCH}

\section{References:}

[1] A. Amann, W. Miekisch, J. Schubert, B. Buszewski, T. Ligor, T. Jezierski, J. Pleil, T. Risby, in Annual Review of Analytical Chemistry, Vol 7, Vol. 7 (Eds: R. G. Cooks, J. E. Pemberton), Annual Reviews, Palo Alto 2014, 455.

[2] J. Leliveld, S. Lechtenbolumer, S. S. Assonov, C. A. M. Brenninkmeijer, C. Dienst, M. Fischedick, T. Hanke, Nature 2005, 434, 841.

[3] J. P. Fitch, E. Raber, D. R. Imbro, Science 2003, 302, 1350.

[4] T. Yu, F. Wang, Y. Xu, L. Ma, X. Pi, D. Yang, Adv. Mater. (Weinheim, Ger.) 2016, 28, 4912.

[5] Y. Wu, D. Zhang, K. Lee, G. S. Duesberg, A. Syrlybekov, X. Liu, M. Abid, M. Abid, Y. Liu, L. Zhang, C. Ó. Coileáin, H. Xu, J. Cho, M. Choi, B. S. Chun, H. Wang, H. Liu, H.-C. Wu, Adv. Mater. Technol. 2016, 10.1002/admt.201600197.

[6] C. Lueng, P. Lupo, P. J. Metaxas, M. Kostylev, A. O. Adeyeye, Adv. Mater. Technol. 2016, 1, 1600097.

[7] K. A. Slinker, C. Kondash, B. T. Dickinson, J. W. Baur, Adv. Mater. Technol. 2016, 1, 1600176.

[8] R. A. Potyrailo, A. Burns, C. Surman, D. J. Lee, E. McGinniss, Analyst 2012, 137, 2777.

[9] R. A. Potyrailo, R. K. Bonam, J. G. Hartley, T. A. Starkey, P. Vukusic, M. Vasudev, T. Bunning, R. R. Naik, Z. Tang, M. A. Palacios, M. Larsen, L. A. Le Tarte, J. C. Grande, S. Zhong, T. Deng, Nat. Commun. 2015, 6, 7959.

[10] J. P. Peixoto, A. H. Oort, Physics of climate, 1992.

[11] J. M. Nassar, M. D. Cordero, A. T. Kutbee, M. A. Karimi, G. A. T. Sevilla, A. M. Hussain, A. Shamim, M. M. Hussain, Adv. Mater. Technol. 2016, 1, 1600004.

[12] H. Arjmandi-Tash, L. A. Belyaeva, G. F. Schneider, Chem. Soc. Rev. 2016, 45, 476.

[13] K. Shehzad, Y. Xu, C. Gao, X. Duan, Chem. Soc. Rev. 2016, 45, 5541.

[14] A. Ghosh, D. J. Late, L. S. Panchakarla, A. Govindaraj, C. N. R. Rao, J. Exp. Nanosci. 2009, 4, 313.

[15] D. J. Late, T. Doneux, M. Bougouma, Appl. Phys. Lett. 2014, 105, 233103.

[16] P. K. Kannan, D. J. Late, H. Morgan, C. S. Rout, Nanoscale 2015, 7, 13293.

[17] C.-C. Chen, M. Aykol, C.-C. Chang, A. Levi, S. B. Cronin, Nano Lett. 2011, 11, 1863.

[18] Y. An, A. Behnam, E. Pop, A. Ural, Appl. Phys. Lett. 2013, 102, 013110.

[19] F. Koppens, T. Mueller, P. Avouris, A. Ferrari, M. Vitiello, M. Polini, Nat. Nanotechnol. 2014, 9, 780.

[20] I. Goykhman, U. Sassi, B. Desiatov, N. Mazurski, S. Milana, D. De Fazio, A. Eiden, J. Khurgin, J. Shappir, U. Levy, Nano Lett. 2016, 16, 3005.

[21] X. Li, H. Zhu, K. Wang, A. Cao, J. Wei, C. Li, Y. Jia, Z. Li, X. Li, D. Wu, Adv. Mater. (Weinheim, Ger.) 2010, 22, 2743.

[22] H.-Y. Kim, K. Lee, N. McEvoy, C. Yim, G. S. Duesberg, Nano Lett. 2013, 13, 2182.

[23] A. Fattah, S. Khatami, C. C. Mayorga - Martinez, M. Medina - Sánchez, L. Baptista - Pires, A. Merkoçi, Small 2014, 10, 4193.

[24] A. Fattah, S. Khatami, IEEE Sens. J. 2014, 14, 4104.

[25] A. Singh, M. Uddin, T. Sudarshan, G. Koley, Small 2014, 10, 1555.

[26] F. Liu, S. Kar, ACS Nano 2014, 8, 10270.

[27] A. C. Ferrari, J. C. Meyer, V. Scardaci, C. Casiraghi, M. Lazzeri, F. Mauri, S. Piscanec, D. Jiang, K. S. Novoselov, S. Roth, A. K. Geim, Phys. Rev. Lett. 2006, 97.

[28] A. C. Ferrari, D. M. Basko, Nat. Nanotechnol. 2013, 8, 235.

[29] W. Wu, Z. Liu, L. A. Jauregui, Q. Yu, R. Pillai, H. Cao, J. Bao, Y. P. Chen, S.-S. Pei, Sens. Actuators, B 2010, 150, 296. 


\section{WILEY-VCH}

[30] X. Li, W. Cai, J. An, S. Kim, J. Nah, D. Yang, R. Piner, A. Velamakanni, I. Jung, E. Tutuc, S. K. Banerjee, L. Colombo, R. S. Ruoff, Science 2009, 324, 1312.

[31] B. Guo, L. Fang, B. Zhang, J. R. Gong, Insciences J 2011, 1, 80.

[32] F. Yavari, C. Kritzinger, C. Gaire, L. Song, H. Gulapalli, T. Borca - Tasciuc, P. M. Ajayan, N. Koratkar, Small 2010, 6, 2535.

[33] D. J. Late, A. Ghosh, B. Chakraborty, A. K. Sood, U. V. Waghmare, C. N. R. Rao, J. Exp. Nanosci. 2011, 6, 641.

[34] L. Khandare, S. S. Terdale, D. J. Late, Adv. Device Mater. 2016, 2, 15.

[35] D. J. Late, Y.-K. Huang, B. Liu, J. Acharya, S. N. Shirodkar, J. Luo, A. Yan, D. Charles, U. V. Waghmare, V. P. Dravid, ACS Nano 2013, 7, 4879.

[36] O. Leenaerts, B. Partoens, F. M. Peeters, Phys. Rev. B 2009, 79, 235440.

[37] T. O. Wehling, A. I. Lichtenstein, M. I. Katsnelson, Appl. Phys. Lett. 2008, 93, 202110.

[38] Y. Xu, C. Cheng, S. Du, J. Yang, B. Yu, J. Luo, W. Yin, E. Li, S. Dong, P. Ye, X. Duan, ACS Nano 2016, 10, 4895.

[39] T. Yu, F. Wang, Y. Xu, L. Ma, X. Pi, D. Yang, Adv. Mater. (Weinheim, Ger.) 2016, 28, 4912.

[40] S. M. Sze, Semiconductor devices: physics and technology, John Wiley \& Sons, 2008.

[41] S. Tongay, M. Lemaitre, X. Miao, B. Gila, B. Appleton, A. Hebard, Phys. Rev. X 2012, 2, 011002.

[42] S. Cheung, N. Cheung, Appl. Phys. Lett. 1986, 49, 85.

[43] A. K. Singh, M. A. Uddin, J. T. Tolson, H. Maire-Afeli, N. Sbrockey, G. S. Tompa, M. G. Spencer, T. Vogt, T. S. Sudarshan, G. Koley, Appl. Phys. Lett. 2013, 102, 043101.

[44] W.-P. Chen, Z.-G. Zhao, X.-W. Liu, Z.-X. Zhang, C.-G. Suo, Sensors 2009, 9, 7431.

[45] A. De Luca, S. Santra, R. Ghosh, S. Ali, J. Gardner, P. Guha, F. Udrea, Nanoscale 2016, 8, 4565.

[46] A. D. Smith, K. Elgammal, F. Niklaus, A. Delin, A. C. Fischer, S. Vaziri, F. Forsberg, M. Råsander, H. Hugosson, L. Bergqvist, Nanoscale 2015, 7, 19099.

[47] M. S. Pawar, P. K. Bankar, M. A. More, D. J. Late, RSC Advances 2015, 5, 88796.

[48] L. D. Bharatula, M. B. Erande, I. S. Mulla, C. S. Rout, D. J. Late, RSC Advances 2016, 6, 105421.

[49] S. Borini, R. White, D. Wei, M. Astley, S. Haque, E. Spigone, N. Harris, J. Kivioja, T. Ryhanen, ACS Nano 2013, 7, 11166.

[50] C. Cao, C. Hu, L. Fang, S. Wang, Y. Tian, C. Pan, J. Nanomater. 2011, 2011, 5.

[51] M. B. Erande, M. S. Pawar, D. J. Late, ACS Appl. Mater. Interfaces 2016, 8, 11548.

[52] U. V. Patil, C. S. Rout, D. J. Late, Adv. Device Mater. 2015, 1, 88.

[53] H. Bi, K. Yin, X. Xie, J. Ji, S. Wan, L. Sun, M. Terrones, M. S. Dresselhaus, Sci. Rep. 2013, 3.

[54] D. Zhang, J. Tong, B. Xia, Sens. Actuators, B 2014, 197, 66.

[55] Y. Yao, X. Chen, H. Guo, Z. Wu, Appl. Surf. Sci. 2011, 257, 7778.

[56] J. L. Fu, F. Ayazi, "Dual-mode piezo-on-silicon resonant temperature and humidity sensor for portable air quality monitoring systems", presented at Sensors, 2010 IEEE, 2010.

[57] W. H. Lim, Y. K. Yap, W. Y. Chong, H. Ahmad, Sensors 2014, 14, 24329.

[58] W. Xuan, M. He, N. Meng, X. He, W. Wang, J. Chen, T. Shi, T. Hasan, Z. Xu, Y. Xu, Sci. Rep. 2014, 4, 7206.

[59] Q. Kuang, C. Lao, Z. L. Wang, Z. Xie, L. Zheng, J. Am. Chem. Soc. 2007, 129, 6070.

[60] T. Islam, M. Z. U. Rahman, IEEE Trans. Instrum. Meas. 2016, 65, 694.

[61] B. Cho, J. Yoon, S. Lim, A. Kim, S.-Y. Choi, D.-H. Kim, K. Lee, B. Lee, H. Ko, M. Hahm, Sensors 2015, 15, 24903.

[62] B. Cho, J. Yoon, M. G. Hahm, D.-H. Kim, A. R. Kim, Y. H. Kahng, S.-W. Park, Y.-J. Lee, S.-G. Park, J.D. Kwon, C. S. Kim, M. Song, Y. Jeong, K.-S. Nam, H. C. Ko, J. Mater. Chem. C 2014, 2, 5280.

[63] M. E. Franke, T. J. Koplin, U. Simon, Small 2006, 2, 36.

[64] S.-R. Guo, J. Lin, M. Penchev, E. Yengel, M. Ghazinejad, C. S. Ozkan, M. Ozkan, J. Nanosci. Nanotechnol. 2011, 11, 5258. 


\section{WILEY-VCH}

[65] R. Pearce, T. lakimov, M. Andersson, L. Hultman, A. L. Spetz, R. Yakimova, Sens. Actuators, B 2011, 155, 451.

[66] Y. Dan, Y. Lu, N. J. Kybert, Z. Luo, A. T. C. Johnson, Nano Lett. 2009, 9, 1472.

[67] R. A. Potyrailo, Chem. Rev. (Washington, DC, U. S.) 2016, 116, 11877.

[68] H. M. J. Al-Ta'ii, Y. M. Amin, V. Periasamy, Sci. Rep. 2016, 6.

[69] D. J. Late, Microporous Mesoporous Mater. 2016, 225, 494. 